\title{
Continent Urinary Diversion
}

National Cancer Institute

\section{Source}

National Cancer Institute. Continent Urinary Diversion. NCI Thesaurus. Code C127175.

A surgical procedure in which segments of the both small and large intestine are incorporated into the urinary tract to create a pouch that collects the urine. 